\title{
Environmental Life Cycle Assessments as Decision Support Systems within Research and Development Processes: Solutions or Confusions for Responsible Innovation?
}

\author{
Steven Flipse ${ }^{1}$ \\ ${ }^{1}$ Delft University of Technology, Netherlands \\ Correspondence: Steven Flipse, Delft University of Technology, Faculty of Applied Sciences, Science \\ Education \& Communication, Lorentzweg 1, 2628CJ Delft, Netherlands. E-mail: S.M.Flipse@tudelft.nl
}

Received: June 14, 2014

Accepted: October 27, $2014 \quad$ Online Published: November 22, 2014

doi:10.5539/ijbm.v9n12p210

URL: http://dx.doi.org/10.5539/ijbm.v9n12p210

\begin{abstract}
Policy makers and scholars from the social sciences encourage innovators to consider broader social and ethical aspects for the responsible development and deployment of new and emerging scientific and technological innovations. Innovators can partly answer this call by conducting product Life Cycle Assessments (LCAs). Yet, how LCAs can help shape responsible innovation remains unclear. This study investigated how innovators actually deploy LCAs, particularly in relation to responsible innovation practices.

In this study, the method of Midstream Modulation, as a form of Socio-Technical Integration Research, is used to observe and interact with researchers on the working floor, to learn how they shape their decisions. These observations are at the basis of five presented narratives that highlight how LCAs are developed and used in corporate research and development practices. These narratives are subsequently analyzed in relation to responsible innovation development.

The results show that, as is proposed in literature, LCAs can indeed be used to quantify the level of environmental impact and as such, can be useful decision aids to select the best, or most sustainable, products and/or production processes. However, the results of this study also show that there are several aspects that cannot be covered just by doing LCAs, yet these aspects are still important for the responsible development and deployment of innovations. In fact, some aspects regarding LCAs cause confusion rather than clarification in relation to responsible innovation development. This paper also shows that through interactions with a critical outsider, through a method such as Midstream Modulation, scientists can learn to become more reflective on their LCA practice, allowing them to include the broader socio-ethical context of innovations on top of calculable environmental impact. This help them answer policy calls for socially responsible innovation, and at the same time contribute to an organization's image in terms of corporate social responsibility.
\end{abstract}

Keywords: life cycle assessments, responsible innovation, social and ethical aspects, decision support, sustainability, marketing, midstream modulation

\section{Introduction}

Policy makers and scholars from the social sciences and humanities encourage public and private innovators to adopt socially responsible innovation (SRI) methods (Van de Poel 2001; $21^{\text {st }}$ Centurty Nanotechnology R\&D Act 2003; Swierstra \& Jelsma 2006; European Group on Ethics 2007; Schuurbiers \& Fisher 2009; European Commission 2011; PBL, 2012). This implies that Research and Development (R\&D) departments focus on the integration of considerations of Social and Ethical Aspects (SEAs) in the scientific and technological parts of innovation trajectories. Such SEAs pertain e.g. to sustainability and environmental impacts of new products and production processes. Inclusion of SEAs has been demonstrated to have a positive effect on R\&D practices, e.g. by helping researchers set better goals and priorities (Van der Burg, 2009; Doorn, 2012; Flipse et al., 2013).

SEA inclusion can also be recommended to improve socially responsible conduct (McWilliams \& Siegel 2001). As such, SEAs are especially important for industry, since the extent to which these SEAs are seriously taken into account can directly influence the marketability and hence economic potential of the innovations under development. However, researchers who work on innovations are generally not aware of the SEAs relevant to 
their work, both within academia and industrial R\&D facilities (Owen \& Goldberg, 2010; Patra 2011; Flipse et al., 2013). Possibly they are preoccupied with their technical work (Brunner \& Ascher, 1992), or even explicitly asked to ignore SEAs (cf. Fisher \& Miller, 2009).

Partly in answer to the call for SRI methods, and partly because of the potential increase in societal acceptability and economic viability of future products and processes, private R\&D departments have adopted the systematic use of environmental Life Cycle Assessments (LCAs) to investigate and analyse the (future) environmental impact of products and processes (e.g. Rebitzer et al., 2004; Hermann et al., 2007) (Note 1). Additionally, LCAs can be used internally, within an organization, to make decisions about which R\&D trajectory to pursue (see e.g. Azapagic, 1999; Khan et al., 2001). However, from an ethnographic perspective, it remains largely unclear how such environmental LCAs are actually developed and used in professional R\&D environments to shape design decisions for new products and processes. As such, it might be possible that important considerations of SEAs are missed or ignored in professional LCAs, which may still be important for responsible innovation practices as envisioned by policy makers and scholars from the social sciences and humanities.

During a three-month study in collaboration with a Dutch industrial company in the field of Life Sciences, the extent to which considerations of SEAs could be integrated into R\&D practice was investigated. Midstream Modulation (Fisher et al., 2006) was used as a method and a framework of analysis of such integration. During this study (see also Flipse et al., 2013), the snaping and use of LCAs within a professional private R\&D department were observed. In this paper an analysis of such shaping and use to support R\&D decisions is presented. An example of how LCAs can indeed be easily used to shape and make R\&D decisions more socially responsibly is highlighted first. Hereafter, several accounts are presented where LCAs do not have the straightforward effect as is proposed in literature.

This paper is structured as follows. Section 2 describes the background and relevance of LCAs in industry. Section 3 presents the methodological part of our investigation. Section 4 describes the results of our observations regarding LCA development and use. Section 5 proposes some recommendations on how to ensure a more structural integration of SEAs in LCA practice and suggests possibilities for further research.

\section{Background of LCAs in private R\&D Environments}

Among other SEAs, sustainability (Note 2) has become an increasingly important theme for industrial product and process developers during the past decades. Large companies currently usually have special sections on their websites dedicated to sustainability and related environmental health and safety aspects, concerning their newest innovations and activities. Indicative of this development is also the large effort that organizations make to end up high in the Dow Jones Sustainability Index. Sustainability has developed into a major theme for SRI practices. Sustainable innovations are usually projected to have lower energy consumption during use and production, less $\mathrm{CO}_{2}$ emission or even $\mathrm{CO}_{2}$ reduction, and less waste production.

Using and producing more sustainable products and processes serves several goals in industry. First, lower energy consumption, less waste and lower $\mathrm{CO}_{2}$ emission may result in lower cost prices and possible tax benefits. Second, sustainability can be a technological performance indicator (less waste, easier production, lower environmental impact) that may be worth a certain (premium) price for potential future buyers. Third, related, lowering the environmental footprint of an organization may improve a company's societal reputation, as sustainable alternatives may be seen as more socially desirable. In turn, this may boost sales.

Currently, many advertisements in consumer based marketing are already based on sustainability claims. Consider e.g. commercials for cars that run on less petrol and emit less $\mathrm{CO}_{2}$, clothing produced with organic cotton, sustainable farming methods for meat and dairy products. While one may discuss the extent to which such products are actually sustainable (in the sense of the Brundtland definition), these advertisements do appear to be successful. Yet in business-to-business environments, the marketing of more sustainable high-tech products may be more difficult. Professionals may be more critical of sustainability related claims than consumers, and purchase related decision-making is more rational than emotional (see e.g. Penders et al., 2009b). In order to be taken seriously, sustainability claims need a certain credibility, which requires a degree of quantifiability. Private organizations need to put sustainability into perspective, allowing future customers to compare the 'level of sustainability' of innovations. R\&D departments therefore invest in calculating exactly how sustainable their new products and processes are. These calculations are combined into environmental LCAs.

LCA calculations can be used in external product communication and marketing, but also within organizations, e.g. to determine whether to pursue the development of this or the next product or production process. The possibilities for this have been explored and presented in literature (see e.g. Rebitzer et al., 2004; Wanichpongpan \& Gheewala, 2006). As such, the outcome of an LCA can play a major role in business 
decisions to continue or halt an R\&D project in early development stages. Later on during development, LCA calculations can be used to make decisions on production facility design and location, in support of financial calculations to determine innovation success chances. Ultimately, when production has commenced in a new or renewed facility, the complete calculated LCA for the new product will be useful in determining the environmental performance of the company, which may be useful when the company participates in e.g. the Dow Jones Sustainability Index. However, an ethnographic description of the use of LCAs in professional R\&D practice and an investigation of the extent to which LCA usage leads to integration of SEAs in such R\&D practice, remains to be presented.

\section{Methods}

In this investigation, Midstream Modulation (MM) (Note 3) is used as both a method and framework of analysis for the integration of SEAs in R \& D practice (Fisher \& Mahajan, 2006, Schuurbiers, 2011). In MM, an 'embedded humanist' interacts with R\&D professionals in their natural environment, i.e. their laboratories and offices, for a period of 12 weeks. This study investigated one large $R \& D$ project within a professional $R \& D$ department in the field of Life Sciences, in which a group of researchers (project director, project managers, business developers, and a team of researchers with their technicians and analysts) aims to develop a process for the sustainable production of a biochemical, which is currently generally produced using petrochemical production alternatives (Note 4).

During weekly interviews, observations in the lab, laboratory meetings, and also lunches, the embedded humanist (Note 5) gets an idea of what the group of R\&D professionals work on, what their considerations are, and how they shape their decisions. Together, the humanist and the professionals explore which SEAs influence research decisions, with the use of the MM protocol. With this protocol, decisions are 'modulated' into subsequent opportunities, considerations, alternatives and prospective outcomes. As such, MM provides opportunities for participant observation, but also for intervention in R\&D practices.

Through increases in 'reflexive awareness' of R\&D professionals on the SEAs that influence their decisions, gradually they start to actively integrate SEAs in their decisions. In the collaboration between the humanist and the R\&D professionals, the latter provide context and the former can provide insights in socio-cultural and socio-political R\&D context. This allows professionals to further broaden their scope of considerations. As such, taking into account SEAs next to technical and economic considerations can help to actually improve the quality of on-going R\&D work (Flipse et al., 2013), while at the same time help answer the call for responsible innovation.

During the use of MM in this 12-week research case study, the embedded humanist had the opportunity to witness the development and use of an LCA for the research project that the R\&D professionals were working on. Based on observations of and discussions about the R\&D work, and on interaction between the members research group and the humanist, the researchers and humanist together identified SEAs that, according to the researchers could have been missed if the humanist had not been present at their R\&D facilities. In the next section, five of such experiences with regard to LCAs are presented in the form of short ethnographic narrative accounts that shows how LCAs are used to shape R\&D decisions. The section also discusses which relevant SEAs were likely to be missed by scientific and technological experts in a professional R\&D environment.

\section{Social and Ethical Aspects in LCA Development and Use}

Calculating a first draft environmental LCA is a difficult task, at least from a technical point of view (Reap et al. 2008). The product is known, but the possible production volumes may still vary. When the study presented in this paper was conducted, it was also still unclear where production would take place and which biological source materials (e.g. corn, wheat or sugar cane) would be available at that location. Each country uses a different electricity network, based on a mix of nuclear, coal, natural gas or sustainable energy, making it difficult to calculate an LCA. Also, the production process is not fully designed yet, so it is unknown which other materials are needed and what kinds of biological side or waste streams are produced. In short, since the location of production is unknown, the LCA cannot be fully calculated, only estimated.

$R \& D$ professionals within the company under study are charged with the task to make these difficult estimations and interpret the results to use them in their R\&D decisions. Below several situations of interaction between the $R \& D$ group's members and the embedded humanist (EH) are described, focusing on particular decisions that professionals made within this research environment. These focus on use of LCAs. The first example shows how one may expect LCAs to be used, to illustrate a positive way in which LCAs can help the inclusion of SEAs in $R \& D$ practice. The other four examples serve as an illustration of how LCAs are difficult to interpret and do not necessarily easily support the integration of SEAs. 


\subsection{Selecting the 'Right' Titrants}

During the research on the fermentation-based production of a biochemical, the team of scientists had to make a decision between a sodium-based titrant vs. a potassium-based alternative. Within the scientific literature, the presented research predominantly uses one of these alternatives. In their own laboratory tests, it appeared that both compounds performed equally well, from a technical perspective: production yields were largely similar with both titrants. One scientist, S1, a fermentation specialist, discussed this with EH during one of their meetings. EH asked what the implications were on the use of both compounds on a much larger scale, in realistic production scenarios. It appeared that also financially, there was no real difference: both compounds were easy to obtain and similarly priced.

However, based on the LCA calculations, one of the components was more favourable; the recycling process of produced side or waste streams significantly differed when using one type of titrant. This implied that S1 would use this particular titrant in all the future research, to represent real-life production conditions. As such, the calculation of the LCA facilitated his decision to choose for one of the two alternatives, even though its use was less common in scientific literature. So, in this example the LCA was easily useable as a decision support tool to facilitate the selection of the most environmentally friendly option. As such, the use of LCAs shaped an R\&D decision which became more socially responsible, and contributed to a more sustainable production method.

\subsection{Energy Usage vs. Capital Expenditures}

Another scientist, S2, was in the lead of the calculation of the LCA for the particular R\&D project under study. S2 was well suited for the task, considering his primary task as a process engineer for the development several processes within the eventual production plant: he knew which compounds would enter the facility, how these are transformed, and which product, side and waste streams are produced during the manufacturing of the biochemical product.

At one point during the design of the production facility, S2 highlighted during a discussion with EH that he had to consider various machines, which would be used for the purification of the end product. He highlighted that there were basically two options: one significantly more expensive machine that was slightly more energy efficient, reducing the energy demand of the production process; and one cheaper machine that consumed slightly more energy. Financially speaking, it seemed more tempting to reduce initial investments and go for the cheaper, less efficient machine, especially considering that the return on investment for the more expensive machine could be several decades. But ultimately, energy consumption reduction also means a financial cost reduction.

The LCA proved to make this machine selection somewhat more difficult: depending on the possible location, the type of energy that would be consumed would have a major impact on the LCA. Even though there was only slightly higher energy consumption with the less efficient machine, if such energy would be primarily produced from coals (which is still normal practice at several locations in the world), this would very much increase the environmental impact (yet reducing the time before the lower investment was earned back). Alternatively, when using more sustainable energy sources, like wind energy or solar energy, the LCAs would be much more favourable (but the financial break-even point would be further in the future). The question was to what extent the company was willing to invest in environmental sustainability.

Personally, S2 preferred to invest more money in a better machine, further decreasing environmental impact. But he was also well aware of corporate considerations regarding investment costs. Together, EH and S2 felt that it might be a good idea not only to frame S2's advice for his preferred choice as a technical and LCA decision, but they also included a societal aspect: choosing the more expensive machine would not only be an investment in a more energy efficient machine (technical perspective), it would also be better for the environment (societal perspective), further improving corporate image, possibly leading to increased sales (economic perspective).

The LCA calculations in this example had another effect. They highlighted the environmental impact of several prospective production locations. The choice articulation for the more expensive and sustainable machine also decreased the number of potential production locations, which were found 'unsustainable'. As such, the LCA facilitated the selection of production locations.

In the end, the more expensive machine was chosen by the project team, which agreed that this would be a good corporate investment. Still, the large focus on environmental sustainability possibly resulted in the omission of other important socio-ethical aspects, pertaining to labour conditions at the various possible locations. While these aspects were later discussed during this midstream modulation study, they were not part of this particular decision example. 


\subsection{Comparison with Alternatives: Petrochemicals Rule}

In another example of the use of LCAs within professional R\&D environments, EH and S2 were discussing the extent to which biologically produced chemicals can actually be considered sustainable, especially in comparison with petrochemical production methods. Research has shown that first generation biofuels can be considered unsustainable, e.g. for the potential stress they place on the production of food commodities (see e.g. Naik et al., 2010). But also viewed from an LCA perspective, production based on biological source materials is no guarantee for a more sustainable production process: the environmental impact of the production of some products may in fact be lower when produced via petrochemical routes instead of biological production routes (see e.g. Lammens et al., 2011). This is somewhat understandable when one considers that petrochemical production processes have been optimised during the last century, while biological production processes have only been developed during the last decades.

When S2 discussed his LCA calculations with EH, he mentioned that at that moment, the biological production pathways and the petrochemical production pathways of the biochemical that was to be produced, only showed a minor difference in environmental impact: the biological pathways were only slightly more favourable. However, it was projected that within some years, when the actual production had commenced, the production process quality had increased so much that it would be significantly more environmentally friendly than the petrochemical alternative.

Being an honest researcher, when asked for an update by corporate management of the current LCA performance of the project, S2 stated that current performance was comparable to petrochemical alternatives. Corporate management picked up on this, and stated that it considered cancelling the entire R\&D project, since the 'level of sustainability' was unsatisfactory. So, in this particular example, LCAs lead to some organizational confusion with regard to the decision to continue or halt the project. This was obviously a huge disappointment for S2 and the rest of the project team, as they had invested much into this project for some years already. Quickly they gathered and contacted corporate management, to indicate that while currently LCA performances were not exclusively positive, they would definitely increase over the next years, while the petrochemical alternative production methods would surely not increase as significantly. Moreover, biological production pathways would be based on biological and hence renewable raw materials, instead of crude oil. Luckily, this further elucidation by the project team convinced management to further pursue this project.

\subsection{Land Use Change}

At some point, S2 and EH discussed the issue of Land Use Change (LUC) that could be inflicted by the production of biobased products. Simply put, there is a certain amount of $\mathrm{CO}_{2}$-equivalents and hence 'global warming potential' in forests; when these (tropical rain)forests make place for arable land for the production of biobased products such as fuels and chemicals, this stored warming potential is released. Generally, LCA calculators distinguish between direct and indirect LUC. For direct LUC, i.e. when one knows what area of forests is 'sacrificed' to make room for arable land, they can estimate the environmental impact quite accurately. However, when it is unknown whether the production of raw materials for a new compound takes place at recently cut-down forests. Yet if one can reasonably predict that the extra amount of arable land would come at the expense of (rain) forest, then one can include indirect LUC into the calculation as well. The effect on LCAs can be quite significant (see e.g. Plevin et al., 2010).

EH and S2 discussed to what extent LUC would be an issue for the production of the developed biochemical. S2 indicated that when he would include direct or indirect LUC into the calculation, the petrochemical alternative would in fact become much more favourable than the biobased alternative: the environmental impact of cutting down forests could be quite significant. Based on the location, the odds of arable land use coming at the expense of forests can increase or decrease, further complicating the LCA calculations. When EH asked how much arable land would actually be necessary to produce the entire world's demand for the biochemical under study, S2 had not considered this question yet. Together they calculated that roughly $30 \mathrm{~km}^{2}$ would be sufficient to satisfy the current worlds' demand, based on a production using first-generation production methods (i.e. only using easily accessible sugars from e.g. corncobs or sugar beets, omitting the use of second generation raw materials, such as stems and other cellulose-based materials). Considering that the amount of arable land in the entire world is roughly 14 million $\mathrm{km}^{2}$, the required $30 \mathrm{~km}^{2}$ could be considered quite insignificant. As such, where the calculated LCA suggested that LUC might be problematic, a further discussion yielded that the effect of LUC would be minimal.

Interestingly, the discussion regarding LUC for the LCA revolved much around the global warming potential and amount of arable land that would be needed for future production. However, other socio-ethical considerations 
that could be important to consider with respect to LUC. E.g, how the loss of (rain) forest might also have an effect on flora and fauna, or indigenous people living in these forests. Still, the discussions of LCAs with regard to LUC further reduced the number of possible production locations; even though it would be unlikely for the new production to have an effect in terms of LUC, the potential for this was considered undesirable by the team.

\subsection{Comparison with Other Calculations: Institutes}

In another example, S2 and EH discussed the value of LCAs for the organization's marketing and communication. The calculations of how much energy is saved in comparison with alternative production methods, and of the extent to which environmental implications are reduced, can provide powerful marketing tools: they might incentivise future customers to choose this product over an alternative. Still, standardised methods (with actual ISO standards) for the calculation of LCAs have only recently started to appear (see e.g. Guinée et al., 2002). Standardisation would allow potential customers to compare data from different organisations. Yet even with standardised methods, there are still many 'unresolved problems' with LCAs, pertaining e.g. to decisions on when LCAs are 'complete,' which parameters to include, and how to weigh and value specific components within an LCA (Reap et al., 2008). Earlier it had already been acknowledged that those who make LCAs could manipulate the calculations based on certain degrees of freedom in the 'standardised' calculations, and that this could render LCAs untrustworthy, turning them into "just another marketing weapon" (Benda et al., 1993, p. 3).

In their discussion, $\mathrm{S} 2$ and $\mathrm{EH}$ concluded that these uncertainties are currently still leading to some confusion in the calculation process, and as such to potential uncertainties or even ambiguities in LCA outcomes. E.g., since the production location is still unknown, the eventual LCA could not be calculated. Also, no final decision had been made on where the LCA calculations would actually end: do you include also transportation to the customer, or does the producer's responsibility for the LCA end when the product leaves the factory gate? With potential production in the order of megatons, and global transportation, this is of major influence on the LCA.

Still, a business unit requires LCA information for early marketing and communication purposes. As such, scientists are asked to make estimations of possible competitors, whose production methods and locations are also unknown. Internally, this leads to situations of tension because of misunderstandings between R\&D and Marketing and Communication ( $\mathrm{M} \& \mathrm{C}$ ). $\mathrm{M} \& \mathrm{C}$ wants to start as early as possible with establishing good customer relations with potential buyers: showing that your product is much better than both the petrochemical and the potential competitors' alternatives is of major importance. For R\&D, thisleads to the question whether LCAs can be considered a trustworthy marketing tool under any circumstance, since completely standardised LCAs do not yet exist. Therefore, potential customers are not facilitated in making informed decisions based on 'trustworthy' LCAs made by different manufacturers.

Notwithstanding, S2 always aims to be as complete and honest as possible in calculating the LCAs, and was highly uncomfortable with the uncertainties surrounding the calculations. His mission is to provide solid factual information to his scientific peers and to his business unit. The solution S2 found to cope with his uncertainties was to have his calculations vetted by an independent, external organization. The Copernicus Institute of Sustainable Development, located in Utrecht, the Netherlands, is an independent, government-funded organization that also makes LCA calculations. S2 provided this institute with his own raw data and asked it to calculate LCAs based on several production scenarios. Interestingly, it turned out that the outcomes were very similar to his calculations. In fact, he found that he had even been more strict on himself, taking more parameters into account than would be strictly necessary according to this independent institute.

This comparative analysis between corporate data and the data of the institute further encouraged the company to present the data as scientifically founded, and vetted by an independent third party. The business unit used the fact that competing organizations had not used external vetting, as another argument to show that this company's product would be the best on the future market: they even had the 'courage' to have their data externally scrutinised. This possibly made the LCA into a more powerful, credible marketing tool in the company's business-to-business environment.

\section{Conclusions and Recommendations}

\subsection{Result Interpretation}

The five narrative accounts illustrate how LCAs are used in innovation practice in one particular case study within the field of industrial Life Sciences. The examples show how difficult it is to calculate a prospective LCA for a product that is currently under development, but also show the use and demand for LCA calculations during such development. While the first example demonstrates how one might expect LCAs to easily work in R\&D 
practice to select the most sustainable production conditions, the other examples show that there can be much more to an LCA than initially meets the eye.

On a meta-level, it seems interesting to note that a very small group of scientists calculate LCAs, while many others within the organization also use their outcomes. These scientists have a large responsibility, considering the large effect the outcome of their calculations have on corporate image and product marketing. Using an LCA in product communication as early as possible is important to demonstrate the potential product benefits to customers. Marketers wish to know what they can actually communicate with certainty, but scientist initially cannot tell them because they simply do not know yet. The interaction between marketing and R\&D departments follows the structure as presented in the Rock Game as described by Mohr et al. (2010): customers and marketers have different demands (e.g. for certainty regarding environmental impact) than scientists can deliver.

Also, organizations and in particular marketers are generally scrutinised for the credibility of their sustainability related claims, which can sometimes be considered by critical customers as unsubstantiated arguments. An example of this can also be found in the Eurobarometer, which highlights that the European public thinks that university scientists do a better job for society than companies when it comes to biotechnology (European Commission 2010). Interestingly, the scientists presented in the narratives in the previous section, all recently finished their PhDs at a public university. Still, these narratives indicate that the scientists wish to develop the best product possible: they prefer the best machines, most sustainable raw materials and least risky production locations. The question is where in the process between sustainability related claim development and active communication, the claims that industrial scientists produce lose their credibility (see e.g. Flipse \& Penders, 2012). In the $R \& D$ project under study, this credibility issue is addressed through the external vetting of claims by an independent third party. Future research could investigate to what extent this external vetting can be considered useful for marketing purposes.

\subsection{Outlook}

The development and use of LCAs appears to be some organizations' way to demonstrate that they take environmental impact seriously. LCAs may be initiated as an answer to policy calls for SRI, and are posited to provide information on the extent to which innovations are sustainable and as such socially responsible, However, making an LCA does not automatically lead to SRI and entrepreneurship. The question remains to what extent LCAs actually can inspire a more socially inclusive innovation environment, or whether it is merely a less desirable form of 'check-box ethics' (Doorn, 2009) leading to a division of moral labour.

Also, while it has been suggested that LCAs cannot give a complete picture for the calculation of environmental impact (see e.g. Hermann et al., 2007), this study shows where the difficulties for LCAs lie in relation to sustainable, responsible innovation also in terms of socio-ethical and socio-economic impact. The many 'unknowns,' e.g. with regard to the production location, raw materials and volumes, further complicate the LCA calculation, but also have ramifications that exceed the company's boundaries in terms of societal effects. Several social and ethical aspects that could be considered important for responsible innovation, such as labour conditions and other social local effects, do not necessarily make their way into LCAs.

Such broader societal context of innovation implementation cannot always be calculated and transfigured into meaningful components of an LCA. Admitted, environmental LCAs are probably not primarily meant for such broader, non-environment related innovation aspects. Still, this warrants the question to what extent LCAs are suitable as 'sustainability quantification tools,' or can be understood as the comprehensive embodiment of sustainability as an innovation theme. The answer is probably that this is only possible to a limited extent with LCAs, and that its development and use has to be accompanied by broader socio-ethical considerations on top of environmental aspects that can be more easily quantified. In that sense, LCAs can be useable as decision aids for responsible innovation, but not as the sole aid on which innovating organisations should rely.

In the study presented in this paper, the role of LCAs as a decision aid next to discussions with an 'embedded humanist' that provides critical feedback on the R\&D process during a three-month field study, was further explored. The presented investigation relied on close interaction between this humanist and the members of a research team in a private R\&D facility. By not having only scientists, but also a critical 'outsider' look at the LCA outcomes, highlighting socio-ethical context, SRI can be further boosted. Such critical interaction can help innovators to become more aware of, and reflect on things that they might have otherwise missed. This study shows that such increased reflexive awareness can further inspire or even strengthen their R\&D decisions, helping the development of a socially inclusive, responsible innovation practice. 


\section{Acknowledgements}

This article is the result of a research project of the CSG Centre for Society and Life Sciences carried out within the research programme of the Kluyver Centre for Genomics of Industrial Fermentation in The Netherlands at the Delft University of Technology, Department of Biotechnology, Section Biotechnology \& Society (BTS), funded by The Netherlands Genomics Initiative (NGI)/ Netherlands Organization for Scientific Research (NWO). Thanks also go to Royal DSM N. V. for hosting this research project, and in particular the Midstream Modulation study participants.

\section{References}

21st Century Nanotechnology Research \& Development Act. (2003). Public Law, 108-153.

Azapagic, A., \& Clift, R. (1999). The application of life cycle assessment to process optimization. Computer \& Chem Eng, 23(10), 1509-1526. http://dx.doi.org/10.1016/S0098-1354(99)00308-7

Benda, J., Narayan, B. J., \& Sticklen, R. J. (1993). Use of Expert Systems for Life Cycle Analysis. SAE Technical Paper Series 930558, Int Congress and Exposition, Detroit.

Brunner, R. D., \&Ascher, W. (1992). Science and Social Responsibility. Policy Sci, 25(3), $295-331$. http://dx.doi.org/10.1007/BF00138787

Doorn, N. (2009). Responsibility ascriptions in technology development and engineering: three perspectives. Sci \& Eng Ethics, 18(1), 69-90. http://dx.doi.org/10.1007/s11948-009-9189-3

Doorn, N. (2012). Exploring Responsibility Rationales in Research and Development (R\&D). Sci Tech \& Hum Values, 37(3), 180-209. http://dx.doi.org/10.1177/0162243911405344

European Commission. (2010). Special Eurobarometer 341/Wave 73.1, TNS Opinion \& Social. Biotechnology Report.

European Commission. (2011). Horizon 2020-The Framework Programme for Research and Innovation. Communication from the Commission to the European Parliament, the Council, the European Economic and Social Committee and the Committee of the Regions, 1-14.

European Group on Ethics in Science and New Technologies to the European Commission. (2007). Opinion on the ethical aspects of nanomedicine-Opinion No. 21. Retrieved from http://ec.europa.eu/bepa/european-group-ethics/docs/publications/opinion_21_nano_en.pdf

Fisher, E., \& Mahajan, R. L. (2006). Midstream Modulation of Nanotechnology Research in an Academic Laboratory. Proceedings of ASME International Mechanical Engineering Congress \& Exposition (IMECE). Chicago, Illinois.

Fisher, E., Mahajan, R. L., \& Mitcham, C. (2006). Midstream Modulation of Technology: Governance from Within. BullSci, Tech \& Soc, 26(6), 485-496. http://dx.doi.org/10.1177/0270467606295402

Fisher, E., \& Miller, C. (2009). Contextualizing the Engineering Laboratory. In Christensen, S. H., Meganck, M. \& Delahousse, B. ( Eds.), Engineering in Context (pp. 369-381). Palo Alto: Academica Press.

Flipse, S. M., \& Penders, B. (2012). Chapter 7-Duurzaam en gezond: Geloofwaardig op de markt. In Van Dam, F., \& Penders, B. (Eds.), Ingrediënten van geloofwaardigheid - Goedetenonderloep (pp. 121-135). The Hague: Boom Lemma Publishers.

Flipse, S. M., Van der Sanden, M. C. A., \& Osseweijer, P. (2013). Midstream Modulation in Biotechnology Industry-Redefining What is 'Part of the Job' of Researchers in Industry. Sci \& Eng Ethics, 19, 1141-1164. http://dx.doi.org/10.1007/s11948-012-9411-6

Guinée, J. B., Gorrée, M., Heijungs, R., Huppes, G., Kleijn, R., De Koning, A....ect (2002). Handbook on life cycle assessment. Operational guide to the ISO standards. Dordrecht: Kluwer Academic Publishers.

Khan, F. I., Natrajan, B. R., \& Revathi, P. (2001). Green Pro: a new methodology for cleaner and greener process design. $J$ of Loss Prevention in Process Ind, 14(4), $307-328$. http://dx.doi.org/10.1016/S0950-4230(00)00047-4

Lammens, T. M., Potting, J., Sanders, J. P. M., De Boer, I. J. M. (2011). Environmental Comparison of Biobased Chemicals from Glutamic Acid with Their Petrochemical Equivalents. Environmental Science \& Technology, 45(19), 8521-8528. http://dx.doi.org/10.1021/es201869e

Mohr, J., Sengupta, S., \& Slater, S. (2010). Marketing of High-Technology Products and Innovations (3rd ed.). Pearson Education Inc. New Jersey. 
Hermann, B. G., Kroeze, C., \& Jawjit, W. (2007). Assessing environmental performance by combining life cycle assessment, multi-criteria analysis and environmental performance indicators. Journal of Cleaner Production, 15(18), 1787-1796. http://dx.doi.org/10.1016/j.jclepro.2006.04.004

McWilliams, A., \& Siegel, D. (2001). Corporate Social Responsibility: A Theory of the Firm Perspective. Acad Man Rev, 26(1), 117-127.

Naik, S. N., Goud, V. V., Rout, P. K., \& Dalai, A. K. (2010). Production of first and second generation biofuels: A comprehensive review. Renewable and Sust Energy Rev, 14(2), 578-597. http://dx.doi.org/10.1016/j.rser.2009.10.003

Owen, R., \& Goldberg, N. (2010). Responsible innovation: a pilot study with the U.K. Engineering and Physical Sciences Research Council. Risk Analysis, 30(11), 1699-1707. http://dx.doi.org/10.1111/j.1539-6924.2010.01517.x

Patra, D. (2011). Responsible Development of Nanoscience and Nanotechnology: Contextualizing Socio-Technical Integration into the Nanofabrication Laboratories in the USA. Nanoethics, 5(2), 143-157. http://dx.doi.org/10.1007/s11569-011-0118-y

Penders, B., Verbakel, J. M. A., \& Nelis, A. (2009a). The Social Study of Corporate Science: A Research Manifesto. BSci, Tech \& Soc, 29(6), 439-446.

Penders, B., Vos, R., \& Horstman, K. (2009b). Sensitization: reciprocity and reflection in scientific practice. EMBO Reports, 10, 205-208. http://dx.doi.org/10.1038/embor.2009.16

PBL Netherlands Environmental Assessment Agency. (2012). Sustainability of biomass in a bio-based economy.

Plevin, R. J., O’Hare, M., Jones, A. D., Torn, M. S., \& Gibbs, H. K. (2010). Greenhouse Gas Emissions from Biofuels' Indirect Land Use Change Are Uncertain but May Be Much Greater than Previously Estimated. EnvSci\& Tech, 44(21), 8015-8021. http://dx.doi.org/10.1021/es101946t

Reap, J, Roman, F., Duncan, S., \& Bras, B. (2008). A survey of unresolved problems in life cycle assessment-Part 2: Impact assessment and interpretation. Int $J$ Life Cycle Assessments, 13, 374-388. http://dx.doi.org/10.1007/s11367-008-0009-9

Rebitzer, G., Ekvall, T., Frischknecht, R., Hunkeler, D., Norris, G., Rydberg, T., Schmidt, W. P., Suh, S., Weidema, B. P., \& Pennington, D. W. (2004). Life cycle assessment: Part 1: Framework, goal and scope definition, inventory analysis, and applications. Env Int, 30(5), 701-720. http://dx.doi.org/10.1016/j.envint.2003.11.005

Schuurbiers, D. (2011). What happens in the Lab Does not Stay in the Lab: Applying Midstream Modulation to Enhance Critical Reflection in the Laboratory. Sci \& Eng Ethics, 17(4), 769-788. http://dx.doi.org/10.1007/s11948-011-9317-8

Schuurbiers, D., \& Fisher, E. (2009). Lab-scale intervention. EMBO Reports, 10(5), 424-427. http://dx.doi.org/10.1038/embor.2009.80

Swierstra, T., \& Jelsma, J. (2006). Responsibility without Moralism in Techno scientific Design Practice. Sci, Tech\& Human Values, 31(3), 309-332. http://dx.doi.org/10.1177/0162243905285844

Van de Poel, I. (2001). The transformation of technological regimes. Research Policy, 32(1), 49-68. http://dx.doi.org/10.1016/S0048-7333(01)00195-0

Van der Burg, S. (2009). Imagining the Future of Photoacoustic Mammography. Sci \& Eng Ethics, 15(1), 97-110. http://dx.doi.org/10.1007/s11948-008-9079-0

Wanichpongpan, W., Gheewala, S. H. (2007). Life cycle assessment as a decision support tool for landfill gas-to energy projects. J Cleaner Production, 15(18), 1819-1826. http://dx.doi.org/10.1016/j.jclepro.2006.06.008

World Commission on Environment and Development (WCED). (1987). Our common future. Oxford: Oxford University.

\section{Notes}

Note 1. As Penders et al. (2009a) describes, it is difficult, if not impossible to determine whether an organisation's motives are purely social or economic in nature. The two probably go hand-in-hand.

Note 2. In this article, the Brundtland definition (WCED, 1987, p. 43) of sustainability is adopted, in relation to 
sustainable development: "Sustainable development is development that meets the needs of the present without compromising the ability of future generations to meet their own needs."

Note 3. In MM, the 'midstream' refers to the process that takes place between 'upstream' funding and 'downstream' implementation of R\&D in society (Fisher et al., 2006). 'Modulation' refers to the guiding activities of the embedded humanist to steer R\&D processes to include also broader SEAs, rather radically change such processes (Rip 2006).

Note 4. The presented study was conducted at the Dutch Life Sciences \& Materials company Royal DSM N.V., a multinational organization with Life Sciences R\&D activities in Delft, the Netherlands. The confidentiality agreement between this company and the author prevents the further disclosure of the names of the group members and the further content and background of their R\&D work, since developments currently are still on-going.

Note 5. The role of the embedded humanist was taken by the author of this paper.

\section{Copyrights}

Copyright for this article is retained by the author(s), with first publication rights granted to the journal.

This is an open-access article distributed under the terms and conditions of the Creative Commons Attribution license (http://creativecommons.org/licenses/by/3.0/). 